\title{
Environmental Communication
}

\section{"Not All Environmentalists Are Like That ...": Unpacking the Negative and Positive Beliefs and Perceptions of Environmentalists}

\author{
Anna Klas, Lucy Zinkiewicz, Jin Zhou \& Edward J. R. Clarke
}

To cite this article: Anna Klas, Lucy Zinkiewicz, Jin Zhou \& Edward J. R. Clarke (2019) "Not All Environmentalists Are Like That...": Unpacking the Negative and Positive Beliefs and Perceptions of Environmentalists, Environmental Communication, 13:7, 879-893, DOI: 10.1080/17524032.2018.1488755

To link to this article: https://doi.org/10.1080/17524032.2018.1488755

View supplementary material $₫$

Submit your article to this journal ¿

山 Article views: 599

Q View related articles ๘

View Crossmark data \lceil

Cas

Citing articles: 4 View citing articles $₫$ 


\title{
"Not All Environmentalists Are Like That ...": Unpacking the Negative and Positive Beliefs and Perceptions of Environmentalists
}

\author{
Anna Klas (iD) ${ }^{a}$, Lucy Zinkiewicz (D) ${ }^{a}$, Jin Zhou ${ }^{a}$ and Edward J. R. Clarke (D) ${ }^{b}$

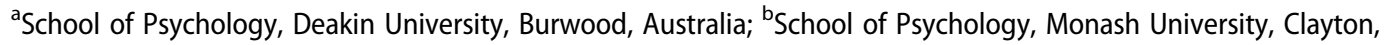 \\ Australia
}

\begin{abstract}
Limited research to date has qualitatively explored the perceptions members of the public who are not environmental activists hold of environmentalists. Therefore a qualitative survey was conducted with 89 US residents aged $21-53\left(M_{\text {age }}=32.74, S D_{\text {age }}=7.89\right)$ to obtain an indepth understanding of how non-activists within the public perceive environmentalists. Data obtained were analyzed using thematic analysis and demonstrated that non-activist perceptions of environmentalists contained both positive and negative components. Environmentalists were seen to value nature and to be actively involved in bringing about positive environmental change (positive component), yet were also viewed as aggressive in their behaviors and stubborn in their beliefs (negative component). Further still, it was found that environmentalists were more likely to be perceived positively when they engaged in individual-level, private sphere behaviors (such as recycling), and negatively when they engaged in collective-level, public sphere behaviors (such as protesting). These findings not only challenge the assumption that members of the public typically evaluate environmentalists negatively, they also outline why some individuals may fail to identify as an environmentalist and engage in pro-environmental behavior. Furthermore, they also provide some insight as to why some environmentalists find it difficult to advocate for system change that results from collective action within the public sphere.
\end{abstract}

\section{ARTICLE HISTORY}

Received 31 October 2017

Accepted 8 June 2018

\section{KEYWORDS}

Qualitative survey; thematic analysis; environmentalist; perceptions; identity

Many environmental problems result, at least partly, from unsustainable human behavior (Swim, Clayton, \& Howard, 2011). Much attention has therefore been given to identifying psychological variables that foster pro-environmental behavior (for some reviews, see Gifford \& Nilsson, 2014; Osbaldiston \& Schott, 2012), with environmental identity often emerging as a stronger predictor than other variables such as environmental attitudes and personal norms (Ruepert et al., 2016; van der Werff, Steg, \& Keizer, 2013c; Whitmarsh \& O'Neill, 2010). This finding has led some to suggest that encouraging members of the general public to identify as an environmentalist may help to improve environmental outcomes (Clayton \& Myers, 2015; van der Werff, Steg, \& Keizer, 2013b, 2014).

However, the way in which a social group is perceived by others within the public sphere contributes not only to whether one will identify with that specific group, but also to whether one will assimilate to and engage in its normative behaviors (Haslam, Oakes, McGarty, Turner, \& Onorato, 1995; Haslam et al., 1996). Therefore we argue that the perceptions members of the public who are not 
environmental activists hold of environmentalists could potentially contribute not only to whether individuals choose to identify as environmentalists, but also whether individuals engage in groupnormative behaviors or hold the same beliefs as the environmentalist social category (Fielding \& Hornsey, 2016; Lacasse, 2016; Ratliff, Howell, \& Redford, 2017; Swim \& Geiger, 2018). Yet, although research has indicated that media representations of environmentalists are typically negative (Drake \& Smith, 2016; Stewart \& Clark, 2011), how members of the public who are not environmental activists (hereon in referred to as non-activist members of the public) generally evaluate environmentalists is not well understood. Given this, we argue that there is a need to investigate the broad perceptions non-activists members of the public hold of all environmentalists and whether the content of these evaluations are only negative in nature. As such, the present research takes a qualitative approach to help illuminate these beliefs and perceptions that are held by non-activists.

\section{Current perspectives on public perceptions of the environmentalist social category}

Where previous research has looked at how environmentalists are perceived by those who do not share their group membership, it has typically examined the views of outgroups who are in conflict with environmentalists (e.g. Colvin, Witt, \& Lacey, 2015; Hutchings, 2005). This research has shown that those in direct conflict with environmentalists over status or specific types of land resources often evaluated environmentalists negatively (Colvin et al., 2015; Fielding, Terry, Masser, Bordia, \& Hogg, 2005; Opotow \& Brook, 2003), while those who strongly subscribed to right-wing ideologies viewed environmentalists as threatening due to the social change environmentalists promoted (Hoffarth \& Hodson, 2016). Other authors have also suggested that other opposing ideological groups with vested interests (such as corporate decision-makers) tend to perceive environmentalists to be anti-progress or anti-technology, as well as uncompromising and unwilling to negotiate (Hutchings, 2005; Murphy \& Dee, 1996; Thatcher, 2014).

It is unsurprising that environmentalists may be viewed negatively by those of whom they are in direct and sustained conflict with, given that groups competing for status and resources tend to view one another negatively in general (Brewer \& Brown, 1998). Yet most of the issues environmentalists engage in conflict over, such as land and water rights, directly impact only specific groups of people who are often small in number (e.g. miners, loggers, or farmers), rather than the general public overall (de Weerd \& Klandermans, 1999; Opotow \& Brook, 2003). As such, we propose that it is possible that perceptions of the environmentalist social category held by non-activists within the public may not be wholly negative.

Other research has also focused on how individuals view various subgroups of environmentalists such as environmental activists (Bashir, 2010), or those who are described as engaging in different types of pro-environmental behaviors (Bashir, Lockwood, Chasteen, Nadolny, \& Noyes, 2013; Castro, Uzelgun, \& Bertolodo, 2016), rather than how non-activists within the public perceive the entire environmentalist social category more generally. Such research has demonstrated that subgroups of environmentalists, such as "tree-huggers" and "radical environmental activists," were evaluated as less likable and more militant than were students (Bashir, 2010). Individuals described as engaging in environmental activism (e.g. protesting) were also perceived to be more aggressive and eccentric than those who were described as engaging in private sphere, individual-level pro-environmental behaviors (e.g. recycling, organic purchasing, energy, and water saving) (Bashir et al., 2013; Castro et al., 2016). Finally, those who are least concerned about climate change tend to view those alarmed about climate change most negatively, while those most concerned about climate change see those individuals who are dismissive of the issue most negatively (Swim \& Geiger, 2018).

Additionally, little work has examined the specific and unique perceptions that non-activists hold of all environmentalists, instead focusing on determining which traits are perceived by outgroup members to be prototypical of certain subgroups of environmentalists (Bashir et al., 2013; Castro et al., 2016; Ratliff et al., 2017). For instance, Castro et al. (2016) showed that those described as engaging in private sphere, individual-level pro-environmental behaviors (e.g. recycling, saving energy, 
and water) were seen as more competent (i.e. "capable," "intelligent," and "competent") and "warmer" (i.e. "good person," "friendly," "warm," "cheerful," and "tolerant") when compared to those described as engaging in environmental collective action. Similarly, Ratliff et al. (2017) demonstrated that respondents who endorsed positive traits (i.e. cool, attractive, fun, intelligent) as prototypical of environmentalists were themselves more likely to engage in pro-environmental behavior. These quantitative studies suggest that some types of environmentalists may be seen less positively than the overall, general environmentalist social category. However, these studies also employed general trait scales not specifically developed to assess the unique perceptions of the environmentalist social category, and therefore it is unclear what specific content makes up the perception non-activists within the public hold of environmentalists in general.

\section{The current study}

The quantitative findings outlined above provide some indication that members of the environmentalist social category (especially environmental activists) may be perceived negatively by those who do not share their group membership (Bashir et al., 2013; Castro et al., 2016; Hoffarth \& Hodson, 2016; Ratliff et al., 2017). Yet, it is still unclear what beliefs and perceptions non-activists - that is, members of the public who are not environmental activists - hold of all environmentalists more generally and whether the content of these evaluations are only negative in nature. Therefore, the current study used a qualitative methodology as it allowed us to examine at depth the perceptions and beliefs that non-activists held of the entire environmentalist social category (not just activists) something quantitative methods do not allow researchers to do (Braun \& Clarke, 2013). Employing a qualitative methodology also ensured that we obtained data that minimized the impact media representations of the group (especially environmental activists) may have had on participant views (Drake \& Smith, 2016; Stewart \& Clark, 2011). Given the qualitative nature of the study, we did not propose a hypothesis, but instead employed the following research question for the current study: how do members of the public who are not environmental activists in general describe and view all environmentalists?

\section{Method}

\section{Participants}

The final sample utilized for the data analysis comprised of 89 participants ( 37 women, 52 men) who did not belong to any environmental organization/s. ${ }^{1}$ Given this, the sample did not include those individuals who are passionate enough to join environmental organizations and therefore be considered environmental activists. Participant age ranged from 21 to 53 years $(M=32.74$, $S D=7.98$ ), with only a small percentage being students $(10.1 \%)$. Participants that provided information concerning their country of origin indicated they were from the United States (one participant did not answer this item). Despite participants not belonging to any environmental organization, a high percentage of participants did indicate they were worried about the current state of the environment $(79,88.8 \%)$, suggesting the sample may have included some environmentalists. Other demographic information (e.g. age breakdown, education level, and annual income) is provided in the supplementary materials.

\section{Data collection}

Once ethics approval was granted by the appropriate Human Research Ethics Committee, an online qualitative survey was conducted via Amazon's Mechanical Turk (MTurk). A qualitative survey was chosen for data collection as this method not only ensures participant anonymity, therefore decreasing the chances that participants will engage in socially desirable responding, it is also an effective 
way to gather data from a larger sample than seen in interactive qualitative approaches (e.g. one-onone interviews) (Frith \& Gleeson, 2008; Opperman, Braun, Clarke, \& Rogers, 2014). Yet, as qualitative surveys employ structured open-ended questions, they still allow for the deep exploration of the ambiguities and complexity in participants' perceptions (Braun \& Clarke, 2013; Toeriena \& Wilkinsonb, 2004). This approach was advantageous over quantitative methodologies as it enabled us to not only look at the traits associated with the environmentalist social category (as seen in typical stereotype research), but also to investigate the broader evaluations, beliefs, and context that surrounded these traits. Consequently, qualitative surveys are well-suited to providing preliminary information for early areas of research when compared to quantitative approaches as they provide researchers with a comprehensive and standardized idea of the perceptions individuals hold on a particular phenomenon (Braun \& Clarke, 2013; Toeriena \& Wilkinsonb, 2004).

The study was advertised in October 2015 for one week on MTurk as a short survey about "the social beliefs you hold about social groups." MTurk was chosen as a recruitment method given MTurk samples are more diverse and representative of the US population than in-person convenience and student samples (Berinsky, Huber, \& Lenz, 2012). No reference to environmentalism was made in the recruitment notice to ensure that those who were not interested in environmentalism did not self-select themselves out of the study. After clicking onto the study link and reading the Plain Language Statement, participants were then directed to the qualitative survey, where they had 15-30 minutes to answer a series of standardized open-ended questions about their views of environmentalists (see Table 1 for item list). Participants wrote an average of 21 words $(M=$ $21.82, S D=18.61$, range $=1-178)$ for each question. Participants' demographics were then collected. Upon submission of the survey, which signified their informed consent, participants were paid \$US1.50.

\section{Data analysis}

Data analysis was guided by the principles of thematic analysis - a flexible yet systematic method of examining recurring categories or "themes" within qualitative data (Braun \& Clarke, 2006, 2013; Clarke \& Braun, 2017). In accordance with this six-stage method, the first two authors (AK, LZ) engaged in an iterative process of identifying, interpreting, and analyzing common themes across participant responses (Braun \& Clarke, 2006). Analysis began with the first author (AK) inductively constructing categories and codes through numerous close readings of participant responses (Morse, 2008). Any remaining data that did not answer the research question was discarded from further analysis (Braun \& Clarke, 2013). These codes, along with the research question, were then used by the first two authors (AK, LZ) as a guide for identifying themes during formal analysis. This analysis occurred across the questions, rather than for each question individually, in order to identify commonalities throughout the data (as this is the major aim of thematic analysis, Braun \& Clarke, 2006). We also investigated whether certain types of demographic categories were more likely to endorse particular themes. Any disagreement between the first two authors (AK, LZ) in terms of the themes generated was resolved through discussion and a re-analysis of coding. These themes were then checked by the third author (JZ). Final confirmation of the themes was made once consensus was reached between the first three authors (AK, LZ, JZ) regarding the content of each theme.

Table 1. Open-ended Questions Employed in the Study.

Question 
We decided that an atheoretical approach was to be taken during data analysis to ensure the qualitative analysis thoroughly explored participant perceptions and was not biased by any assumptions made by a psychological theory. Nevertheless, a thematic analysis devoid of a grounding theoretical framework still requires an epistemological position to be made evident (as suggested by Braun \& Clarke, 2006, 2013). Given this, we adopted a critical realist perspective during data analysis and write-up (Carter \& Little, 2007) as this asserts that an independent, objective reality exists, but also recognizes that the way in which reality is experienced by individuals is often socially constructed by their culture and demographic characteristics (Sims-Schouten, Riley, \& Willig, 2007; Wikgren, 2005). This epistemological position is also often taken in conjunction with a thematic analysis approach (Braun \& Clarke, 2006, 2013). Employing this epistemological position meant that participants' responses could be taken as they were and interpreted as depicting the reality of people's perceptions surrounding environmentalists, without minimizing the contribution that the wider social context may have had upon these social cognitions.

\section{Analysis and discussion}

Four major synthesized themes were identified across the majority of participants, with only a few key demographic differences found within these four themes (a table providing a definition, quotation, and demographic differences in an endorsement for each theme is provided in the supplementary materials). No significant changes were made to the quotations used below, except for the correction of minor spelling mistakes in order to increase the readability and comprehension of the data (otherwise known as "cleaning the data," see Braun \& Clarke, 2013; Sandelowski, 1994).

Unique identifier numbers, rather than pseudonyms, are used for each participant due to the anonymous nature of the data (e.g. participant one was labeled as P1, participant two was labeled as $\mathrm{P} 2$, etc.). In order to provide an idea of the strength of the broad perceptions participants held of environmentalists, quantifying terms are employed as suggested by Braun and Clarke (2013). Following the guideline in Opperman et al. (2014), the terms "majority" or "most" are used when more than two thirds of participants provided the same or similar perception $(>66)$; "frequently" is employed when perceptions were offered by close to half of participants $(>44)$; "some" is employed when less than half of participants offered that specific interpretation $(<43)$; and the term "a few" is employed when less than a quarter of participants offered a specific opinion $(<22)$.

\section{Theme 1: all environmentalists care about and value nature}

Theme 1 reflects how the majority of participants, regardless of their gender, age, educational level, or annual income, perceived every member of the environmentalist social category to hold a number of core pro-environmental beliefs and values. In particular, participants described that, even though "there are many different kinds of environmentalists" (P45), all environmentalists would share the same pro-environmental beliefs and values regarding the need to "protect the environment from the forces of man [sic]" (P85) and to "preserve the planet we live on" (P12). For non-activist members of the public, holding beliefs and values that emphasize the importance of the natural environment can be seen to be one of the defining characteristics of the environmentalist social category, extending upon research that has attempted to define what it means to be an environmentalist (Holland, Tesch, Kitchell, \& Kempton, 2000; Tesch \& Kempton, 2004; Tranter, 2010). In fact, this finding suggests that definitions of environmentalists should explicitly reference concern for the natural environment as something unique to that social group, and confirms that participants saw the environmentalist social category as an opinion based group (Swim \& Geiger, 2018).

When unpacking the specific content of the pro-environmental beliefs and values held, the language participants commonly employed (regardless of age, gender, education level, or annual income) indicated that all environmentalists were believed to share a deep concern for the quality of the natural environment. For instance, environmentalists were described as "caring deeply" 
(P95) or "sincerely caring" (P87) about "the state of the environment" (P84) and "treating the planet well" (P21). In fact, the majority of participants employed terms such as "care" (P4), "cares" (P10), "caring" (P67), or "concerned" (P96) when describing environmentalists. Even a few participants who indicated they were not worried about the current state of the environment (P36, P50, P61, P64) described environmentalists as being caring, while some participants who were below the age of 35 even extended the realm of what environmentalists cared about beyond nature itself, to also include the "future of the planet" (P15), "animals and their natural habitat" (P28), as well as "future generations" (P12).

Across responses and demographic categories, the majority of participants also suggested that all environmentalists would "value nature" (P1) regardless of benefit to themselves or to others - that is, every environmentalist would hold strong biospheric values (Steg \& de Groot, 2012). This finding extends previous research which shows that biospheric values predict whether an individual selfidentifies as an environmentalist (Gatersleben, Murtagh, \& Abrahamse, 2014; van der Werff, Steg, \& Keizer, 2013a), by showing that a diverse range of non-activists within the public also unequivocally perceive holding biospheric values to be essential to being an environmentalist. Instances of this perception were explicitly observed when participants frequently described environmentalists as "nature lovers" (P18), "one with nature" (P42), "in harmony with nature" (P62), and "connected to nature" (P61). This valuing of nature was also implied when some participants (who were typically male and over the age of 35) described how environmentalists would "do anything to help the (environment)" (P52) because they valued "keep(ing) nature clean" (P87) and "conserving the world's natural spaces, animals, and oceans" (P90). Some participants who were highly educated even perceived environmentalists to value the natural environment so much that they "equated the importance of the environment about the same as they would another human being" (P70) reflecting recent work demonstrating how environmentalists can humanize or anthropomorphize the natural environment (Tam, Lee, \& Chao, 2013).

Some participants, regardless of demographic categories, also employed well-known labels that directly referenced environmentalists' valuing of nature, including "greenie" (P50), "hippie" (P20), "tree-hugger" (P69), "naturalist" (P100), and "conservationist" (P31). Although a few participants over the age of 30 acknowledged these labels could be employed negatively by others in the general public (e.g. "all the sneering that's done by the mainstream [about environmentalists] as 'dippy hippies' and 'climate alarmists"' (P90)), most participants regardless of demographic categories (age, gender, education level, and concern for the environment) typically offered these labels in a neutral way, devoid of any positive or negative connotations. These findings give some weight to previous suggestions that these labels are used as slurs against environmentalists and their cause by those who are ideologically opposed to the group (Hutchings, 2005; Thatcher, 2014; Wright, Nyberg, \& Grant, 2012), yet also indicate that these terms are not used as wholly negative labels by non-activist members of the public. Indeed, it may be that only when in direct and sustained conflict with environmentalists over environmental issues do non-activists employ these labels negatively, which is consistent with research showing negative reactions that certain groups have to environmentalists when in direct conflict with the group (Fielding et al., 2005; Murphy \& Dee, 1996; Opotow \& Brook, 2003).

\section{Theme 2: all environmentalists are active in protecting, conserving, and improving nature}

This second theme outlines how most participants specified that all environmentalists must engage in a variety of pro-environmental "steps" (P59) or "actions" (P98) at the "individual, local, national, or international level" (P63) to be considered an environmentalist. This insistence that environmentalists "actively care" (P10) was clearly seen across all participants, regardless of gender, age, education level, or annual income, with environmentalists explicitly described as "active" (P37), "actively working" (P24), "actively advocating" (P1), "actively involved" (P22), "actively trying” (P87), or "(taking) action" (P26) (however, participants who indicated they were worried about 
the environment were more likely to describe environmentalists as active). Other times this need for "activeness" was implied in responses, with environmentalists described as "always making some effort" (P48), "willing to put everything they've got into that one goal" (P64), or "willing to speak up" (P16).

The overwhelming emphasis by the majority of participants on pro-environmental action when describing environmentalists suggests that this engagement in pro-environmental behaviors is perceived to be as essential to being an environmentalist as holding pro-environmental beliefs and values (see Theme 1). This is in contrast to previous work where self-identified environmentalists saw those who held pro-environmental attitudes, but took no action, to still be a part of the social group (Holland et al., 2000; Tesch \& Kempton, 2004).

As participants across demographic categories saw being active to be one of the defining characteristics of the environmentalist social category, data were further explored to determine what types of pro-environmental behaviors were considered to be especially prototypical of the group.

An environmentalist in my mind is someone ... who is green in everything that they say and do, drives a Prius, recycles, things that Captain Planet ${ }^{2}$ would endorse. (P12)

An environmentalist is someone who cares about the environment and takes care of it to the best of their ability. They recycle their glass, paper, metal and aluminum. They reduce their usage of electricity, gas and water. They buy products made out of recycled material. And they may even drive electric cars. (P33)

An environmentalist is someone who cares about the world around us and wants to maintain a healthy world vs destroying it. To do this they do things such as track their carbon footprint, recycle and reuse, and buy things that are good for our environment instead of detrimental to it. (P53)

An environmentalist is a person that is actively involved in preserving the environment. They recycle and buy sustainable products as well as engaging in environmental activism by protesting or circulating a petition. (P46)

As evidenced in the extracts above, numerous types of pro-environmental behaviors were seen by participants to be prototypical of the environmentalist social category, aligning with prior research demonstrating the multifactorial nature of pro-environmental behavior (e.g. Dono, Webb, \& Richardson, 2010; Larson, Stedman, Cooper, \& Decker, 2015; Markle, 2013). In particular, it appeared that the pro-environmental behaviors specified by participants could be classified according to Stern's (2000) pro-environmental behavior categories, in that these actions included those that occur within the private ("usage of electricity, gas and water," P33) and public ("circulating a petition," P46) spheres as well as those that are conceptualized as occurring at the individual ("They recycle their glass, paper, metal and aluminium," P33) and collective ("protesting," P46) level.

Nevertheless, deeper analysis of these behaviors showed that it was those "lifestyle" (P72) actions that occurred in the private sphere and at the individual-level that were most commonly offered by participants as being prototypical of all environmentalists. Although five participants (P50, P55, P61, P81, and P100) explicitly labeled environmentalists as "activists" (P100), it is important to note that the majority of participants did not make any direct reference to environmentalists engaging in collective action. This was seen across gender, age, and education level. This finding implies that, although being individually active is seen as an important component of the broader environmentalist social category according to non-activists, engaging in an activist role may not be ${ }^{3}$. This finding could be due to the individualistic culture (the US) from which participants came which often advocates for individual action and free-market strategies over collective action when attempting to solve environmental issues (Akenji, 2014). However this finding is in direct contrast to some previous work that has implied that being an environmentalist is synonymous with being an environmental activist (Bashir et al., 2013; Stewart \& Clark, 2011).

While activism was rarely touched upon by participants, a few participants, who were typically male and had attended university, did view environmentalists through a politically based lens. This was evident when environmentalists were described with such political terms as "liberals at heart" (P79), "leftist" (P73), "progressive" (P74), or "socially aware" (P89). These findings suggest 
that environmentalists are seen as falling to the left side of the political spectrum, thus potentially reflecting the politically polarized nature of current environmental issues (Dunlap, McCright, \& Yarosh, 2016; Layman, Carsey, \& Horowitz, 2006; McCright, Xiao, \& Dunlap, 2014). These participant perceptions mirror recent quantitative research showing that those who hold low rates of right-wing ideologies do indeed demonstrate higher rates of pro-environmental attitudes and behavior (Stanley, Wilson, \& Milfont, 2017a; Stanley, Wilson, Sibley, \& Milfont, 2017b) and are less likely to deny climate change (Clarke, Ling, Kothe, Klas, \& Richardson, 2018; Hornsey, Harris, Bain, \& Fielding, 2016).

\section{Theme 3: most environmentalists are altruistic and self-sacrificing}

Although it has been previously found that others can hold negative evaluations of those who engage in environmental activism (Bashir, 2010; Bashir et al., 2013; Castro et al., 2016; Drake \& Smith, 2016; Stewart \& Clark, 2011), Theme 3 outlines how the broader perceptions non-activist members of the public held of environmentalists also contained positive components. This was evident in participants' frequent descriptions of environmentalists as "good" (P8), "genuine" (P22), "passionate" (P81), "dedicated" (P5), "informed" (P15), and "honorable" (P34), especially in responses to the first two items of the survey (see Table 1). Analysis of who used these terms and when showed that participants across demographic categories often employed these descriptors in conjunction with their explanations of how environmentalists are actively involved in helping the environment (e.g. "I think most are to be admired for the efforts they put forth in helping protect the environment," P35). This implies that participants perceived environmentalists positively at least partly due to their "activeness" and engagement in numerous pro-environmental behaviors, especially those "lifestyle" behaviors that could be considered individual-level, private sphere behaviors (which itself was seen as a defining characteristic of the broader environmentalist social category, see Theme 2).

Positive views of the environmentalist social category were also frequently linked to the contributions of the group. For instance, environmentalists were "working for a great cause" (P1) and had "an important role" (P35) for society as they "raise(d) awareness about environmental issues" (P40), "educated those who may not know better" (P16), and provided "potential solutions to environmental issues" (P90). A few participants, who were typically male and concerned for the environment, even emphasized that they "admired" (P80) and "respected" (P86) environmentalists because they "operated according to their principles" (P63) (although two participants who were not worried about the environment also stated that they respected environmentalists - P64, P61). Others noted that environmentalists were "stewards" (P88) of the earth because "environmentalists work or live in such a way to reduce the negative consequences of human impact" (P88). These findings not only align with previous work that shows environmental stewardship is a central component of environmentalism (Larson et al., 2015), but also suggests that environmentalists may be perceived positively precisely because of the stewardship role they undertake.

Given the findings outlined above, it is somewhat unsurprising that participants frequently described environmentalists as selfless. For example, environmentalists were "self-sacrificing" (P67), "unselfish" (P5), or "altruistic in the way that they are willing to sacrifice things for the good of people in the future" (P8). A few participants even suggested that environmentalists received "little credit" (P2) for their selfless actions:

I think (environmentalists) are unselfish because generally being an environmentalist and living an environmentally friendly life style means making sacrifices so that society, future generations, and nature can benefit. It's usually not immediately self-serving to be an environmentalist, and sometimes could even hold the person back or inconvenience them. (P72)

However, further analysis of participant responses revealed that the positive perceptions participants held of the environmentalist social category were conditional on which types of pro-environmental 
behaviors environmentalists choose to engage in. This was evident across gender, age, education level, or whether participants were worried about the environment. Examples of this conditionality can be seen in the caveats participants included when explaining their views of environmentalists (underlined emphases added by authors):

(I view them as) generally positive as long as they don't get militant with their agenda. (P19)

I have a neutral view on them, so long as they don't try to force their lifestyle on me. (P83)

I think they can be great as long as they are not extremists or willing to kill people for their beliefs. (P52)

Anybody looking to do good is right by me but I think forcing people to do things because of your agenda can be a bit overwhelming and a bit of a put off even if people agree with what you're trying to accomplish. (P40)

So long as environmentalists don't go to extremes to push their views, I have nothing but respect for them. (P70)

I think there are some that go to unnecessary extremes, but generally environmentalists just want to do what they can to help. (P71)

The language used above suggests that participants only maintained their positive evaluations of environmentalists as being informed, caring, and dedicated "so long" as environmentalists did not "force" their views on others, engage in what were perceived to be socially undesirable behaviors such as radical or militant collective action, or try to forcefully change others' behaviors. This finding extends upon research showing those who engage in environmental activism are perceived as extreme, aggressive, and militant (Bashir et al., 2013; Castro et al., 2016), by suggesting that the broader environmentalist social category is actually initially perceived positively by non-activists, due to environmentalists' engagement in private sphere individual-level pro-environmental behaviors. It is only when environmentalists engage in more forceful public and collective action that could directly impact others or the broader social system that these positive perceptions turn negative. This implies that, for environmentalists, maintaining a positive impression within the public may involve constraining their pro-environmental behaviors to only private sphere, individuallevel actions. This also suggests that the "typical" environmentalist may not be perceived negatively as a typical environmentalist is not seen to engage in activism (as suggested by Bashir et al., 2013); rather a "typical" environmentalist is one that engages in individual-level pro-environmental behavior and because of this may be perceived positively at first.

\section{Theme 4: not all environmentalists are extreme and aggressive, but many act that way}

While most participants initially emphasized the "goodness" of environmentalists, this final theme outlines how participants regardless of age, gender, or whether they were worried about the environment also simultaneously held negative perceptions of the environmentalist social category (as hinted at in the discussion of Theme 3). Indeed, after many participants outlined the positive traits they saw as prototypical of environmentalists (e.g. informed, caring, selfless, dedicated), they would then frequently offer negative traits as also being prototypical of the group. Many of these negative traits emphasized how "extreme" (P98) some types or subgroups of environmentalists could become, by either explicitly using such terms as "zealots" (P78), "intense" (P87), and "hard-core" (P36), or implicitly in descriptions of being "over the top" (P99), getting "carried away and going overboard" (P53), or going to "unnecessary extremes" (P71). This is certainly consistent with former suggestions that environmentalist activists can be viewed as extreme by outgroup members (Drake \& Smith, 2016; Hutchings, 2005; Murphy \& Dee, 1996; Stewart \& Clark, 2011), yet it also appears that this perception of "extremism" could be held concurrently with perceptions of all environmentalists being "caring" or "concerned" (see Themes 1 and 3).

Nevertheless, a few participants went a step beyond seeing environmentalists as extreme, by also suggesting that members of the group were "aggressive" (P50), "arrogant" (P47), "unrealistic" (P63), 
and "stubborn" (P24) in their beliefs and behaviors. Some described environmentalists as getting "on a bit of a high horse about how much good they do" (P75), being "so egotistical and didactic that it (turned) people off the movement" (P74), as well as being "overly idealistic" (P63) in the goals that they were trying to achieve:

The environmentalists I see talk of unrealistic goals - zero net carbon emissions (we'd basically have to go to a pre-industrial age), non-pesticide food (which means less food and more hunger), and a widespread conversion to solar power (ignoring the fact that few areas are suitable for it). (P66)

These findings extend on previous research that has examined the possible negative perceptions of environmentalist activists (Bashir et al., 2013; Castro et al., 2016; Ratliff et al., 2017) by identifying the specific traits that may make up the negative content of this perception (e.g. aggressive, stubborn, unrealistic, etc.).

The way in which some environmentalists interacted with the public - including when attempting to influence others - was also perceived to be problematic. For example, a few participants, who were typically female, outlined how environmentalists sometimes found it difficult to talk to those who held a "different view" (P34) because they could be too "biased and closed minded" (P64) or were "unable to hear any kind of counter-argument" (P24). Some participants who tended to be female and university educated also highlighted how environmentalists could at times be too "heavy handed" (P36) in their tactics, especially "when trying to convince sceptics" (P36). These views suggest that for non-activist members of the public an environmentalist may simply be ineffective in persuading them to care about the environment or to engage in pro-environmental behavior, due to the perception that some environmentalists are too argumentative or biased. This finding highlights the importance of considering the source of pro-environmental messages when attempting to persuade members of the general public who do not identify as environmentalists to engage in pro-environmental behaviors (Fielding \& Hornsey, 2016; Greenaway, Wright, Willingham, Reynolds, \& Haslam, 2015).

It is important to note that, when outlining their negative views of environmentalists, many participants who were often male and university educated did use strategic phrases to emphasize they did not view all environmentalists as extreme and forceful, just a subgroup of environmentalists who tended to engage in collective action. Examples include "there are some that go to unnecessary extremes" (P71), "most of them are well-meaning" (P50), and "just like any group, they (have) a far wing of their movement who will do anything" (P27). The use of such terms as "some," "most," or "like any group" by participants was strategic as it allowed them to indicate that they did not think negatively of every single environmentalist, while simultaneously still providing them the opportunity to outline the negative evaluations they held of certain types of environmentalists. While this could have occurred because participants were attempting to avoid being seen to stereotype the social category, that these overall negative views were frequently offered by participants suggests that these negative aspects were still explicitly associated with group.

\section{Implications and conclusion}

The aim of the present study was to explore how environmentalists are viewed by members of the public who were not environmental activists or advocates (i.e. those who are not passionate or concerned enough to belong to environmental organizations). This was done in order to obtain a deeper understanding of the perceptions non-activist members of the public held of environmentalists as a whole, and whether the content of this evaluation was solely negative. As we were interested in obtaining an in-depth understanding of these perceptions and beliefs, we employed a qualitative methodology for the current study, with the following research question used to guide our thematic analysis: how do members of the public who are not environmental activists in general describe and view all environmentalists? 
One of the key implications that arises from the current study is that non-activists appear to perceive the defining characteristics or features of the environmentalist social category to be both group members' shared ideology and their engagement in pro-environmental behaviors. Therefore, for non-activists at least, for one to be considered an environmentalist they must not only be concerned for the environment and hold biospheric values (as suggested by Theme 1), but they must also engage in a broad range of pro-environmental behaviors, especially individual-level private sphere behavior (as indicated in Theme 2). These findings clarify previous research which has attempted to define an environmentalist by emphasizing that both one's beliefs and behaviors should be considered when determining whether one can be seen as an environmentalist (Holland et al., 2000; Tesch \& Kempton, 2004; Tranter, 2010). They also help to explain why studies reframing individuals' past behaviors as being pro-environmental increases the likelihood that they will self-identify or label themselves as an environmentalist (Lacasse, 2016; van der Werff et al., 2013a) as it appears it is one's engagement in pro-environmental behavior and therefore "activeness" that defines the group.

The findings of the current study also suggest that the broader public perception of environmentalists contains both positive and negative components that may initially make individuals evaluate the group ambivalently (as seen with climate change opinion groups in Swim \& Geiger, 2018). However, it appears that it is only when environmentalists engage in individual or collective behaviors do either negative or positive evaluations become salient to the public in a given situation. This finding extends previous research that has showed that environmentalists are typically evaluated negatively by those with differing ideologies (Hoffarth \& Hodson, 2016; Hutchings, 2005; Murphy \& Dee, 1996), by suggesting such negative perceptions are more likely when environmentalists choose to engage in collective, public sphere behaviors that challenge the status quo and may even destabilize the system (e.g. protesting). Yet when environmentalists choose to engage in individualistic, private sphere behaviors, members of the public may be more likely to emphasize the positive components of the environmentalist social category - perhaps because environmentalists are no longer challenging the system (Bashir et al., 2013; Castro et al., 2016). This finding therefore also has implications for the environmental movement more broadly, especially since some subgroups of environmentalists argue that system-based solutions which arise from collective action (rather than individual, personal behaviors) are the only way to ensure adequate progress is made in minimizing current global environmental issues (Holland et al., 2000; Tesch \& Kempton, 2004). Yet the collective tactics often needed to achieve these systembased solutions appear to be negatively perceived by the public and could even potentially discourage non-activists within the public from joining environmental causes or engaging in proenvironmental behavior - thus minimizing the likelihood of positive environmental outcomes (as also suggested by Bashir et al., 2013).

Finally, a more general implication of the current study relates to how the perceptions non-activists hold of the environmentalist social category may contribute to their willingness to identify as an environmentalist, which is strongly predictive of a range of pro-environmental behaviors (van der Werff et al., 2013a, 2013b, 2013c; Whitmarsh \& O’Neill, 2010). Our findings point to two potential reasons as to why some individuals may fail to identify as an environmentalist in the first place, even when potentially being concerned for the environment (as indicated by the large component of the sample stating that they were worried about the current state of the environment). Firstly, it could be that when negative components of the environmentalist stereotype are made salient, especially as a result of environmentalists engaging in what is seen as extreme behavior, members of the public may be less likely to identify as an environmentalist (and therefore less likely to engage in pro-environmental behaviors themselves). Secondly, and perhaps more importantly, not identifying as an environmentalist may be due to environmentalists being seen to be defined by outgroup members by their beliefs and constant pro-environmental behavior. This perception may in actuality limit non-activist members of the public environmentalist identification as they may not feel they engage in enough behaviors to be considered an environmentalist. 


\section{Limitations and future directions}

Although this study provided a deeper understanding of the way non-activist members of the general public view environmentalists, a number of limitations must be noted. Firstly, given the qualitative nature of the study and that it only recruited US participants, it is difficult to draw causal inferences and generalizations from this study. It is entirely possible that different cultures hold different perceptions of environmentalists, especially if these cultures do not subscribe to individualistic worldviews such as those held by the US. Investigating cross-cultural differences in the perceptions members of the public hold of environmentalists is likely to provide a fruitful area for future research.

Additionally, data concerning ethnicity, political party affiliation, and political ideology were not collected in this study. Yet ethnicity is a prominent demographic category within the US, while debates around environmental issues within the US have also become increasingly politically polarized (Dunlap et al., 2016; McCright et al., 2014). For instance, recent research has demonstrated that conservatives tend to view environmentalists as especially threatening to the status quo (Hoffarth \& Hodson, 2016). Given this, ethnicity and political ideology may have contributed to how participants perceived environmentalists, and should be explored as a potential moderator in future studies examining perceptions of environmentalists.

Finally, it is possible that the perceptions offered by participants would have changed if they were asked to recall, for example, an instance where they directly interacted with environmentalists, especially whether those environmentalists engaged in collective action or lifestyle behaviors. Given the importance of social context to group perceptions (Haslam et al., 1995), and that direct and sustained intergroup conflict can heighten negative evaluations of outgroups (Brewer \& Brown, 1998; Colvin et al., 2015; Fielding et al., 2005), it is entirely possible that the valence of certain perceptions offered by participants could have intensified or diminished depending on the social context. Future research should examine how past positive and negative experiences with environmentalists contribute to which negative or positive perceptions become salient to members of the public.

\section{Concluding remarks}

Given little research has investigated how members of the public who are not activists view all environmentalists, the aim of this qualitative study was to obtain an in-depth understanding of how these individuals perceived the broad environmentalist social category (not just environmental activists). Results of the qualitative survey demonstrated that the majority of participants perceived environmentalists to be caring and altruistic, particularly because environmentalists valued the natural environment and were actively engaged in individual-level private sphere behaviors that helped to improve the natural environment. However, most participants also simultaneously viewed some types of environmentalists to be extreme and aggressive, especially those that attempted to change others' opinions or behaviors, or engaged in collective action within the public sphere. These findings have implications not only for the current assumption that most in the public evaluate environmentalists wholly negatively, but also for why some individuals may fail to identify as an environmentalist at all and why those environmentalists who advocate for system-based solutions for environmental problems find it difficult to convince non-activists for their need.

\section{Notes}

1. One hundred participants were initially recruited for the current study. However, to ensure that all participants were not activists or advocates for the environment, membership in an environmentalist organization was used to determine whether one was an environmental activist. This was because it was reasoned that an environmentalist activist would be passionate enough about the natural environment that they would be involved in an environmental organization in some capacity - either as an active member or as a financial contributor. As 
such, participants who indicated that they were members of an environmental organization $(n=7)$, not sure if they were $(n=1)$, or preferred not to say $(n=3)$ were deleted from all further data analyses.

2. Captain Planet is a US children's animated television show that has a focus on environmental sustainability.

3. We do acknowledge that many environmentalists see themselves as activists, even those who only engage in individual-level, private sphere pro-environmental behaviours (as seen in Tesch \& Kempton, 2004). However, in the context of this study, participants appear to view environmental activism as a subcomponent of the broader environmentalist social category and something that not all environmentalists do.

\section{Disclosure statement}

No potential conflict of interest was reported by the authors.

\section{ORCID}

Anna Klas (D) http://orcid.org/0000-0002-6590-5164

Lucy Zinkiewicz (D) http://orcid.org/0000-0002-1861-1673

Edward J. R. Clarke (D) http://orcid.org/0000-0002-6441-7150

\section{References}

Akenji, L. (2014). Consumer scapegoatism and limits to green consumerism. Journal of Cleaner Production, 63, $13-23$. doi:10.1016/j.jclepro.2013.05.022

Bashir, N. Y. (2010). "Green" doesn't always make good impressions: Evaluations of different types of environmentalists (Doctoral thesis, University of Toronto, Canada). Retrieved from http://tspace.library.utoronto.ca

Bashir, N. Y., Lockwood, P., Chasteen, A. L., Nadolny, D., \& Noyes, I. (2013). The ironic impact of activists: Negative stereotypes reduce social change influence. European Journal of Social Psychology, 43(7), 614-626. doi:10.1002/ejsp. 1983

Berinsky, A. J., Huber, G. A., \& Lenz, G. S. (2012). Evaluating online labor markets for experimental research: Amazon.com's mechanical Turk. Political Analysis, 20(3), 351-368. doi:10.1093/pan/mpr057

Braun, V., \& Clarke, V. (2006). Using thematic analysis in psychology. Qualitative Research in Psychology, 3(2), 77101. doi:10.1191/1478088706qp063oa

Braun, V., \& Clarke, V. (2013). Successful qualitative research: A practical guide for beginners. London: SAGE.

Brewer, M. B., \& Brown, R. J. (1998). Intergroup relations. New York: McGraw-Hill.

Carter, S. M., \& Little, M. (2007). Justifying knowledge, justifying method, taking action: Epistemologies, methodologies, and methods in qualitative research. Qualitative Health Research, 17(10), 1316-1328. doi:10.1177/ 1049732307306927

Castro, P., Uzelgun, M. A., \& Bertolodo, R. (2016). Climate change activism between weak and strong environmentalism: Advocating social change with moderate argumentation strategies? In C. Howarth \& E. Andreouli (Eds.), The social psychology of everyday politics (pp. 1-22). London: Routledge.

Clarke, E. J., Ling, M., Kothe, E. J., Klas, A., \& Richardson, B. (2018, April 30). Perceived mitigation threat mediates effects of right-wing ideology on climate change beliefs. doi:10.17605/OSF.IO/3T9TG

Clarke, V., \& Braun, V. (2017). Thematic analysis. Journal of Positive Psychology, 12(3), 297-298. doi:10.1080/ 17439760.2016 .1262613

Clayton, S. D., \& Myers, G. (2015). Conservation psychology: Understanding and promoting human care for nature (2nd ed.). Chichester: Wiley Blackwell.

Colvin, R. M., Witt, G. B., \& Lacey, J. (2015). The social identity approach to understanding socio-political conflict in environmental and natural resources management. Global Environmental Change, 34, 237-246. doi:10.1016/j. gloenvcha.2015.07.011

de Weerd, M., \& Klandermans, B. (1999). Group identification and political protest: Farmers' protest in the Netherlands. European Journal of Social Psychology, 29(8), 1073-1095.

Dono, J., Webb, J., \& Richardson, B. (2010). The relationship between environmental activism, pro-environmental behaviour and social identity. Journal of Environmental Psychology, 30(2), 178-186. doi:10.1016/j.jenvp.2009.11.006

Drake, P., \& Smith, A. (2016). Belligerent broadcasting, male anti-authoritarianism and anti-environmentalism: The case of top gear (BBC, 2002-2015). Environmental Communication, 10(6), 689-703. doi:10.1080/17524032.2016. 1211161

Dunlap, R. E., McCright, A. M., \& Yarosh, J. H. (2016). The political divide on climate change: Partisan polarization widens in the U. S. Environment: Science and Policy for Sustainable Development, 58(5), 4-23. doi:10.1080/ 00139157.2016.1208995 
Fielding, K. S., \& Hornsey, M. J. (2016). A social identity analysis of climate change and environmental attitudes and behaviors: Insights and opportunities. Frontiers in Psychology, 7(121), doi:10.3389/fpsyg.2016.00121

Fielding, K. S., Terry, D. J., Masser, B. M., Bordia, P., \& Hogg, M. A. (2005). Explaining landholders' decisions about riparian zone management: The role of behavioural, normative, and control beliefs. Journal of Environmental Management, 77(1), 12-21. doi:10.1016/j.jenvman.2005.03.002

Frith, H., \& Gleeson, K. (2008). Dressing the body: The role of clothing in sustaining body pride and managing body distress. Qualitative Research in Psychology, 5(4), 249-264. doi:10.1080/14780880701752950

Gatersleben, B., Murtagh, N., \& Abrahamse, W. (2014). Values, identity and pro-environmental behaviour. Contemporary Social Science, 9(4), 374-392. doi:10.1080/21582041.2012.682086

Gifford, R., \& Nilsson, A. (2014). Personal and social factors that influence pro-environmental concern and behaviour: A review. International Journal of Psychology, 49(3), 141-157. doi:10.1002/ijop.12034

Greenaway, K. H., Wright, R. G., Willingham, J., Reynolds, K. J., \& Haslam, S. A. (2015). Shared identity is key to effective communication. Personality and Social Psychology Bulletin, 41(2), 171-182.

Haslam, S. A., Oakes, P. J., McGarty, C., Turner, J. C., \& Onorato, R. S. (1995). Contextual changes in the prototypicality of extreme and moderate outgroup members. European Journal of Social Psychology, 25(5), 509-530.

Haslam, S. A., Oakes, P. J., McGarty, C., Turner, J. C., Reynolds, K. J., \& Eggins, R. A. (1996). Stereotyping and social influence: The mediation of stereotype applicability and sharedness by the views of in-group and out-group members. British Journal of Social Psychology, 35(3), 369-397. doi:10.1111/j.2044-8309.1996.tb01103.x

Hoffarth, M. R., \& Hodson, G. (2016). Green on the outside, red on the inside: Perceived environmentalist threat as a factor explaining political polarization of climate change. Journal of Environmental Psychology, 45, 40-49. doi:10. 1016/j.jenvp.2015.11.002

Holland, D., Tesch, D., Kitchell, A., \& Kempton, W. (2000). Identities and actions within environmental groups. Human Ecology Review, 7(2), 1-20.

Hornsey, M. J., Harris, E. A., Bain, P. G., \& Fielding, K. S. (2016). Meta-analyses of the determinants and outcomes of belief in climate change. Nature Clim. Change, 6(6), 622-626. doi:10.1038/nclimate2943

Hutchings, K. (2005). Don. $t$ call me a tree hugger!: Sticks, stones, and stereotypes in ecocriticism. Interdisciplinary Literary Studies, 7(1), 5-26.

Lacasse, K. (2016). Don't be satisfied, identify! Strengthening positive spillover by connecting pro-environmental behaviors to an "environmentalist" label. Journal of Environmental Psychology, 48, 149-158. doi:10.1016/j.jenvp. 2016.09.006.

Larson, L. R., Stedman, R. C., Cooper, C. B., \& Decker, D. J. (2015). Understanding the multi-dimensional structure of pro-environmental behavior. Journal of Environmental Psychology, 43, 112-124. doi:10.1016/j.jenvp.2015.06.004

Layman, G. C., Carsey, T. M., \& Horowitz, J. M. (2006). Party polarization in American politics: Characteristics, causes, and consequences. Annual Review of Political Science, 9, 83-110. doi:10.1146/annurev.polisci.9.070204.105138

Markle, G. L. (2013). Pro-environmental behavior: Does it matter how it's measured? Development and validation of the Pro-Environmental Behavior Scale (PEBS). Human Ecology, 41(6), 905-914. doi:10.1007/s10745-013-9614-8

McCright, A. M., Xiao, C., \& Dunlap, R. E. (2014). Political polarization on support for government spending on environmental protection in the USA, 1974-2012. Social Science Research, 48, 251-260. doi:10.1016/j.ssresearch. 201.06.008

Morse, J. M. (2008). Confusing categories and themes. Qualitative Health Research, 18(6), 727-728. doi:10.1177/ 1049732308314930

Murphy, P., \& Dee, J. (1996). Reconciling the preferences of environmental activists and corporate policymakers. Journal of Public Relations Research, 8(1), 1-33.

Opotow, S., \& Brook, A. T. (2003). Identity and exclusion in rangeland conflict. In S. Clayton \& S. Opotow (Eds.), Identity and the natural environment (pp. 249-272). Cambridge, MA: MIT Press.

Opperman, E., Braun, V., Clarke, V., \& Rogers, C. (2014). "It feels so good it almost hurts": Young adults' experiences of orgasm and sexual pleasure. Journal of Sex Research, 51(5), 503-515. doi:10.1080/00224499.2012.753982

Osbaldiston, R., \& Schott, J. P. (2012). Environmental sustainability and behavioral science: Meta-analysis of proenvironmental behavior experiments. Environment and Behavior, 44(2), 257-299. doi:10.1177/0013916511402673

Ratliff, K. A., Howell, J. L., \& Redford, L. (2017). Attitudes toward the prototypical environmentalist predict environmentally friendly behavior. Journal of Environmental Psychology, 51, 132-140. doi:10.1016/j.jenvp.2017.03.009

Ruepert, A., Keizer, K., Steg, L., Maricchiolo, F., Carrus, G., Dumitru, A., \& Moza, D. (2016). Environmental considerations in the organizational context: A pathway to pro-environmental behaviour at work. Energy Research and Social Science, 17, 59-70. doi:10.1016/j.erss.2016.04.004

Sandelowski, M. (1994). Notes on qualitative methods: Notes on transcriptions. Research in Nursing \& Health, 17, $311-314$.

Sims-Schouten, W., Riley, S. C. E., \& Willig, C. (2007). Critical realism in discourse analysis. Theory \& Psychology, 17 (1), 101-124. doi:10.1177/0959354307073153

Stanley, S. K., Wilson, M. S., \& Milfont, T. L. (2017a). Exploring short-term longitudinal effects of right-wing authoritarianism and social dominance orientation on environmentalism. Personality and Individual Differences, 108, 174-177. doi:10.1016/j.paid.2016.11.059 
Stanley, S. K., Wilson, M. S., Sibley, C. G., \& Milfont, T. L. (2017b). Dimensions of social dominance and their associations with environmentalism. Personality and Individual Differences, 107, 228-236. doi:/10.1016/j.paid. 2016.11.051

Steg, L., \& de Groot, J. I. M. (2012). Environmental values. In S. D. Clayton (Ed.), The Oxford handbook of environmental and conservation psychology. (pp. 81-92). New York, NY, US: Oxford University Press.

Stern, P. C. (2000). New environmental theories: Toward a coherent theory of environmentally significant behavior. Journal of Social Issues, 56(3), 407-424. doi:10.1111/0022-4537.00175

Stewart, J., \& Clark, T. (2011). Lessons from South Park: A comic corrective to environmental puritanism. Environmental Communication, 5(3), 320-336. doi:10.1080/17524032.2011.584545

Swim, J. K., Clayton, S., \& Howard, G. S. (2011). Human behavioral contributions to climate change: Psychological and contextual drivers. American Psychologist, 66(4), 251-264. doi:10.1037/a0023472

Swim, J. K., \& Geiger, N. (2018). The gendered nature of stereotypes about climate change opinion groups. Group Processes \& Intergroup Relations, 21(3), 438-456. doi:10.1177/1368430217747406

Tam, K.-P., Lee, S.-L., \& Chao, M. M. (2013). Saving Mr. Nature: Anthropomorphism enhances connectedness to and protectiveness toward nature. Journal of Experimental Social Psychology, 49(3), 514-521. doi:10.1016/j.jesp.2013.02. 001

Tesch, D., \& Kempton, W. (2004). Who is an environmentalist? The polysemy of environmentalist terms and correlated environmental actions. Journal of Ecological Anthropology, 8(1), 67-83. doi:10.5038/2162-4593.8.1.4

Thatcher, V. L. (2014). The atypical environmentalist: The rhetoric of environmentalist identity and citizenship in the Texas coal plant opposition movement (Doctoral thesis). University of Texas at Austin, US. Retrieved from http:// utexas-ir.tdl.org

Toeriena, M., \& Wilkinsonb, S. (2004). Exploring the depilation norm: A qualitative questionnaire study of women's body hair removal. Qualitative Research in Psychology, 1(1), 69-92. doi:10.1191/1478088704qp006oa

Tranter, B. (2010). Environmental activists and non-active environmentalists in Australia. Environmental Politics, 19 (3), 413-429. doi:10.1080/09644011003690898

van der Werff, E., Steg, L., \& Keizer, K. (2013a). I am what I am, by looking past the present: The influence of biospheric values and past behavior on environmental self-identity. Environment and Behavior, 46(5), 626-657. doi:10.1177/0013916512475209

van der Werff, E., Steg, L., \& Keizer, K. (2013b). It is a moral issue: The relationship between environmental self-identity, obligation-based intrinsic motivation and pro-environmental behaviour. Global Environmental Change, 23(5), 1258-1265. doi:10.1016/j.gloenvcha.2013.07.018

van der Werff, E., Steg, L., \& Keizer, K. (2013c). The value of environmental self-identity: The relationship between biospheric values, environmental self-identity and environmental preferences, intentions and behaviour. Journal of Environmental Psychology, 34, 55-63. doi:10.1016/j.jenvp.2012.12.006

van der Werff, E., Steg, L., \& Keizer, K. (2014). Follow the signal: When past pro-environmental actions signal who you are. Journal of Environmental Psychology, 40, 273-282. doi:10.1016/j.jenvp.2014.07.004

Whitmarsh, L., \& O’Neill, S. (2010). Green identity, green living? The role of pro-environmental self-identity in determining consistency across diverse pro-environmental behaviours. Journal of Environmental Psychology, 30(3), 305314. doi:10.1016/j.jenvp.2010.01.003

Wikgren, M. (2005). Critical realism as a philosophy and social theory in information science? Journal of Documentation, 61(1), 11-22. doi:10.1108/00220410510577989

Wright, C., Nyberg, D., \& Grant, D. (2012). "Hippies on the third floor": Climate change, narrative identity and the micro-politics of corporate environmentalism. Organization Studies (01708406), 33(11), 1451-1475. doi:10.1177/ 0170840612463316 